\title{
Frank Allen (1944-2014), member of the Editorial Board of Structural Chemistry
}

\author{
Istvan Hargittai
}

(C) Springer Science+Business Media New York 2015

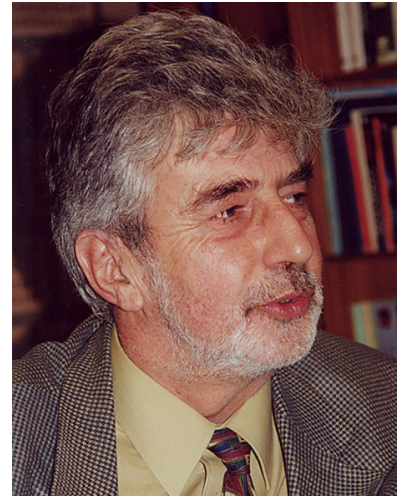

Frank Allen (photo by I. Hargittai)

Frank Allen was a crystallographer with a PhD degree from Imperial College (London). Following a postdoctoral stint in Vancouver he returned to his native England and in 1970 he joined the Cambridge Crystallographic Data Centre. He rose to the position of Scientific Director and Executive Director of the Centre. He was a pioneer in data management and data mining. He retired in 2008 but did not retire from crystallography.

Frank was for many years member of our Editorial Board. It was reassuring to know that we could turn to him for reviewing manuscripts in which the authors used large amounts of structural information for making conclusions. $\mathrm{He}$ was gentle but rigorous in his criticism, always constructive.

I have known Frank for decades, first from the literature, later we met at conferences and the Erice schools, and corresponded about journal business. Our field of structural science will miss him; our journal and our community will miss him.

\section{Hargittai $(\bowtie)$}

Department of Inorganic and Analytical Chemistry,

Budapest University of Technology and Economics,

POBox 91, 1521 Budapest, Hungary

e-mail: istvan.hargittai@gmail.com 